\title{
Reimagining pH Measurement: Utilizing Raman Spectroscopy for Enhanced Accuracy in Phosphoric Acid Systems
}

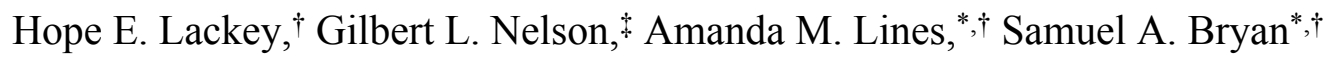 \\ $\dagger$ Energy and Environment Directorate, Pacific Northwest National Laboratory, Richland, Washington 99352, United \\ States \\ \$Department of Chemistry, College of Idaho, 2112 Cleveland Boulevard, Caldwell, Idaho 83605, United States \\ *Email: amanda.lines@pnnl.gov; sam.bryan@pnnl.gov
}

\section{Supplementary Information}

SI contains a figure comparing $\mathrm{pH}$ and $\mathrm{p}\left[\mathrm{H}^{+}\right]$based on the MCR calculations, HySS models and $\mathrm{pH}$ probe measurements. This material is available free of charge via the Internet at http://pubs.acs.org. 

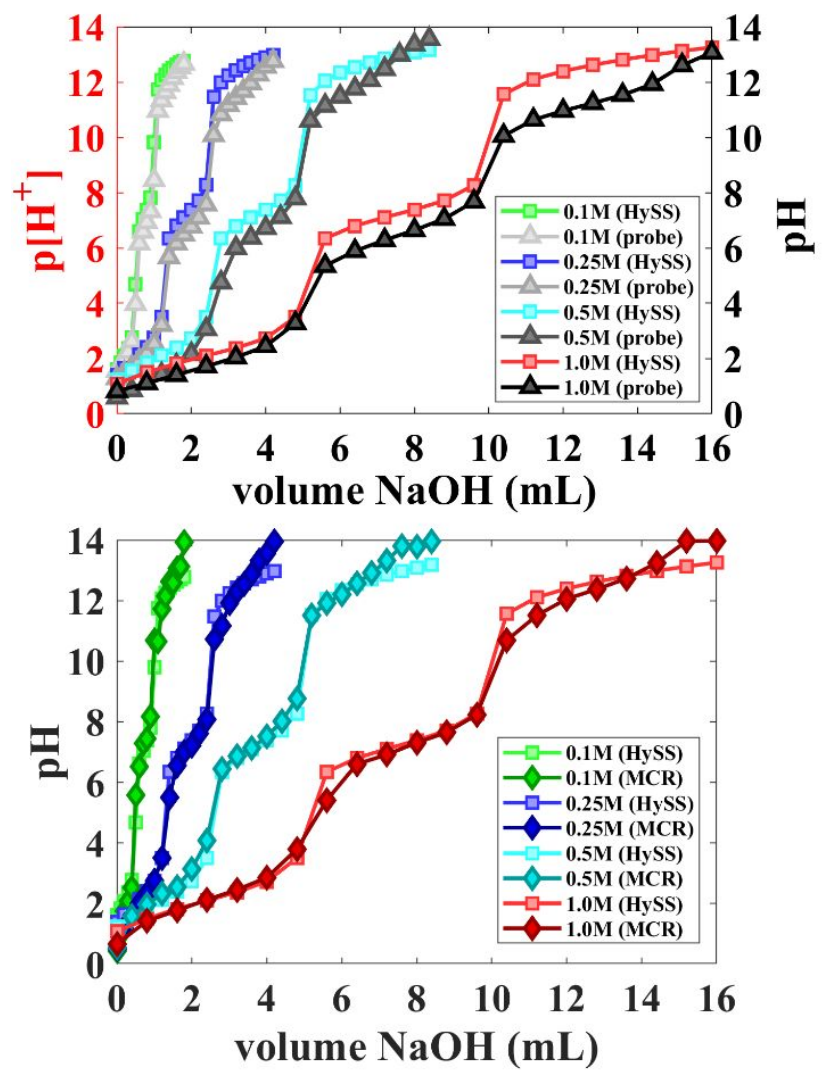

Figure S1 Titration curves of validation set data showing $\mathrm{pH}$ and $\mathrm{p}\left[\mathrm{H}^{+}\right]$changes as base is added to phosphoric acid systems from 0.1 to $1.0 \mathrm{M}$, as measured by a traditional $\mathrm{pH}$ probe versus the commercially available HySS software (top), and as predicted by MCR chemometric models versus the HySS software (bottom). 